\title{
Educación financiera en píldoras: jeroglíficos financieros y posts en el Portal del Cliente Bancario
}

\author{
Inés Andújar Nagore \\ Personal técnico del Banco de España (Madrid, España) \\ ines.andujar@bde.es | https://orcid.org/0000-0002-8491-5595
}

Este trabajo ha sido seleccionado para su publicación por: don Manuel Area Moreira, don Julio Barroso Osuna, doña Ana García-Valcárcel Muñoz-Repiso, don José Hernández Ortega y don Javier de los Ríos Medina.

\section{Extracto}

La educación financiera de los usuarios bancarios tiene un carácter eminentemente práctico. Esta -entendida como combinación de conocimientos, actitudes y conductas- permite tomar decisiones de gasto, ahorro y endeudamiento informadas, responsables y sostenibles en el tiempo, lo cual es indispensable para asegurar el bienestar financiero, individual y colectivo: no hay más que remitirse a la última crisis financiera para recordar las desastrosas consecuencias económicas y sociales derivadas, entre otras causas, de decisiones financieras desinformadas e irresponsables de una gran masa de consumidores. Sin embargo, a pesar de su trascendencia, los datos muestran un analfabetismo generalizado de la población (España no es una excepción) y un escaso interés por conocer los rudimentos financieros más básicos. En este contexto, estimular la curiosidad de los ciudadanos por sus finanzas personales y familiares se presenta como un auténtico reto para aquellos que trabajamos en el ámbito educativo-institucional. Este trabajo explora algunas claves para ello, adoptando un enfoque conductual, y presenta una aplicación práctica materializada en dos series de contenidos educativos publicados en el Portal del Cliente Bancario del Banco de España, analizando su impacto, así como sus limitaciones y potencialidades.

Palabras clave: educación financiera; jeroglíficos financieros; Portal del Cliente Bancario; ciencias de la conducta. 


\title{
Financial education in pills: financial riddles and posts in the Bank Customer Portal
}

\author{
Inés Andújar Nagore
}

\begin{abstract}
Financial education of bank users essentially has a practical nature. Financial education -understood as a combination of knowledge, attitudes and behaviours-allows us to take decisions of expenditure, saving and indebtedness with responsibility, information and sustainability. This is indispensable to ensure the financial welfare, both individual and collective: if we follow the past financial crises, we can remember the disastrous economic and social consequences due to, among other factors, uninformed and irresponsible financial decisions of a mass of consumers. However, in spite of its importance, data shows a generalised illiteracy of the population (Spain is not an exception) and a scarce interest for knowing the most basic financial rudiments. Within this context, to stimulate the citizens' curiosity for their personal and family finances is a real challenge for those who work in the educational-institutional sphere. This work explores some keys for this, adopting a behavioural scope, and presents a practical implementation materialised in two series of educational contents published in the Bank Customer Portal of Banco de España. It also analyses their impact, limitations and potentialities.
\end{abstract}

Keywords: financial education; financial riddles; Bank Customer Portal; behavioural science.

Citation: Andújar Nagore, I. (2022). Financial education in pills: financial riddles and posts in the Bank Customer Portal. Tecnología, Ciencia y Educación, 21, 81-114. https://doi.org/10.51302/tce.2022.634 


\section{Sumario}

1. Introducción

2. La educación financiera

2.1. Analfabetismo financiero de la población: evidencia empírica

2.2. Situación de la educación financiera en España

3. El enfoque conductual

3.1. Heurísticas o atajos mentales

3.2. Sesgos cognitivos

3.3. Las aplicaciones del enfoque conductual en la educación financiera

4. De la teoría a la práctica: series de contenidos para la educación financiera

4.1. El Portal del Cliente Bancario

4.2. Serie «Jeroglíficos Financieros»

4.3. Serie «Decisiones con Cabeza»

4.4. Una valoración de su impacto

5. Limitaciones, potencialidades y conclusión

Referencias bibliográficas

Nota: los puntos de vista expresados por la autora en este artículo son personales y no reflejan, necesariamente, los del Banco de España. 


\section{Introducción}

Principalmente desde el año 2000, organismos internacionales, como la Organización para la Cooperación y el Desarrollo Económicos (OCDE), el Fondo Monetario Internacional, el G20 y la Comisión Europea, están prestando una atención prioritaria al fomento de la educación financiera de la población. En el ámbito nacional, el gobernador del Banco de España, entre otras autoridades, se ha referido también a la educación financiera de los ciudadanos en diversas intervenciones (Hernández de Cos, 2019). ¿A qué se debe tanto interés?

Podría decirse que la preocupación por la cultura financiera de los ciudadanos se explica, principalmente, por la confluencia de varios factores:

- La asimetría existente en las relaciones cliente-banco.

- La creciente complejidad del mercado financiero.

- La evolución demográfica y social que está experimentando nuestro entorno.

- El alcance económico y social de las decisiones financieras individuales.

En efecto, en primer lugar, es fácilmente constatable que las relaciones entre los bancos y sus clientes son generalmente «asimétricas». En contraste con la entidad financiera, al usuario medio le resulta difícil acceder a la información completa sobre los términos y las cláusulas de los productos y servicios financieros que contrata, y carece de los conocimientos técnicos y especializados para comprenderlos e interpretarlos adecuadamente. Como consecuencia de esta asimetría, los consumidores financieros están expuestos a prácticas de venta poco adecuadas y ofertas inapropiadas para sus perfiles (OCDE, 2009).

A esta dificultad inherente se suma la creciente tendencia a la complejidad que está experimentando el mercado financiero. La aplicación de la «innovación tecnológica» a la práctica bancaria (la llamada fintech) está llevando al desarrollo de nuevos productos financieros y nuevas vías para su comercialización y contratación, principalmente digitales. En este entorno, surgen productos y desarrollos cada vez más sofisticados y difíciles de comprender para los usuarios, que, al mismo tiempo que les brindan ciertas oportunidades y facilidades, también les acarrean riesgos, como la ciberdelincuencia, la vulneración de sus datos personales o la tentación de sucumbir a ofertas de crédito rápidas (OCDE, 2018). Esto contribuye a incrementar su vulnerabilidad, especialmente en el caso de determinados colectivos sociales -como, por ejemplo, el de las personas mayores- menos familiarizados con las nuevas tecnologías. 
Por otro lado, es bien sabido que la sociedad española, al igual que los países de nuestro entorno, presenta una «tendencia demográfica» hacia el envejecimiento debido a la reducción de la natalidad y al aumento de la longevidad. Todo ello, unido a los mayores costes que el cuidado de la salud conlleva y al riesgo de pérdida del poder adquisitivo de las pensiones públicas, incrementa la responsabilidad de los ciudadanos en la planificación y gestión de sus finanzas personales (Hernández de Cos et al., 2017).

Por último, un cuarto factor es el «impacto y alcance de las decisiones financieras de los individuos». Como bien puso de manifiesto la pasada crisis financiera, las decisiones financieras de las personas, tomadas sin la suficiente capacitación financiera, pueden acarrear consecuencias negativas, no únicamente sobre su propio bienestar, presente y futuro, sino también sobre el conjunto de la sociedad y la economía (OCDE, 2009).

No es de extrañar, pues, que en este contexto, la «educación financiera»-entendida como la combinación de conocimientos, actitudes y conductas que permiten tomar decisiones financieras sensatas y lograr un bienestar financiero individual (OCDE, 2017)- se erija como una importante herramienta para proteger a los usuarios financieros ${ }^{1}$, mantener la confianza en el mercado y garantizar su eficiencia y estabilidad

En estos últimos tiempos de pandemia, la educación financiera de la ciudadanía se muestra incluso más crucial para asegurar la «resiliencia financiera» frente al desempleo y al impacto económico (Campbell et al., 2011). En estos últimos tiempos de pandemia, la educación financiera de los ciudadanos se muestra incluso más crucial para asegurar la «resiliencia financiera» frente al desempleo y al impacto económico que la crisis de la COVID-19 está causando sobre los ingresos y ahorros de la población (OCDE, 2020a).

Sin embargo, a pesar de su trascendencia, se observa que los usuarios bancarios adolecen de un «analfabetismo financiero» generalizado: no solo carecen de conocimientos financieros básicos y son víctimas de una evidente asimetría informativa, sino que también muestran un conocimiento limitado para interpretar correctamente la información y un comportamiento inconsistente y sesgado que los lleva, en muchos casos, a tomar malas decisiones de ahorro, gasto y endeudamiento (Van Raaij, 2016). Por ejemplo, Bucks y Pence (2008) evidencian, para una muestra de individuos que tienen contratado un préstamo hipotecario a tipo variable, que, si bien sí parecen conocer los términos básicos de

1 La educación financiera se concibe como una herramienta de protección de los usuarios financieros "por el lado de la demanda» que se suma y complementa a las herramientas "por el lado de la oferta»: la regulación y la supervisión de las entidades financieras en materia de transparencia y buenas prácticas bancarias (Andújar y Tejada, 2019). 
su contrato de hipoteca, infravaloran o ignoran el riesgo de variación de los tipos de interés en el que están incurriendo, con el consecuente peligro de no poder asumir subidas en su cuota mensual ante incrementos de tipos. La adopción de un enfoque conductual para mejorar la comprensión del comportamiento de los consumidores parece, pues, valioso para asegurar unas mejores políticas de protección de los usuarios bancarios (Campbell et al., 2011).

Con el objetivo de estimular el interés y el conocimiento de los consumidores por sus finanzas personales y familiares, este trabajo explora los sesgos más comunes en los que incurren -incurrimos- los usuarios bancarios en materia financiera y pasa de la teoría a la práctica con una propuesta educativa consistente en dos series de contenidos publicados en el Portal del Cliente Bancario del Banco de España en el segundo semestre de 2019. El trabajo evalúa, asimismo, su impacto en la web y analiza sus limitaciones y potencialidades para seguir avanzando en la educación financiera del gran público.

El orden de exposición será el siguiente: el apartado 2 presenta el estado actual de la educación financiera de la población (en el mundo y en España) y el apartado 3 recoge sucintamente algunas de las principales aportaciones del enfoque conductual y sus potenciales aplicaciones en el ámbito de la educación financiera. Teniendo en cuenta estas consideraciones, el apartado 4 presenta una propuesta práctica de educación financiera a través del Portal del Cliente Bancario y analiza su impacto en la web. Finalmente, el apartado 5 reflexiona sobre sus limitaciones y potencialidades y extrae conclusiones de esta experiencia educativa.

\section{La educación financiera}

\subsection{Analfabetismo financiero de la población: evidencia empírica}

Un reciente informe de la OCDE (2020a) reúne evidencia empírica de los conocimientos, comportamientos y actitudes financieras de población adulta encuestada en 26 países del G20. En él se concibe la educación financiera como un conjunto de conocimientos, comportamientos y actitudes medidas a través de una serie de indicadores:

- Conocimientos financieros. Siete sencillas preguntas tipo test, con una sola respuesta correcta, sobre los conceptos de inflación, interés simple y compuesto, diversificación del riesgo y relación entre riesgo y rentabilidad.

- Comportamientos financieros. Nueve preguntas sobre el seguimiento (o no) de las siguientes conductas consideradas positivas para mejorar el bienestar financiero: 
- Usar un presupuesto para la gestión del dinero.

- Asumir la responsabilidad en las decisiones financieras dentro de la unidad familiar.

- Considerar cuidadosamente la contratación de productos financieros antes de realizarla.

- Pagar los recibos a tiempo.

- Vigilar asiduamente las finanzas personales, por ejemplo, revisando los movimientos de la cuenta.

- Ahorrar activamente.

- En situaciones de déficit financiero (ingresos menores a los gastos), contar con un «colchón» suficiente que evite recurrir al endeudamiento.

- Tener objetivos a largo plazo y esforzarse por lograrlos.

- Informarse y comparar opciones antes de adquirir un producto financiero.

- Actitudes hacia la planificación financiera en el largo plazo. Tres proposiciones valorables con una escala de 1 a 5 según el grado de acuerdo (de menor a mayor) por parte del encuestado:

- «Tiendo a vivir el presente. El futuro ya vendrá».

- «Encuentro más satisfactorio gastar dinero que ahorrarlo a largo plazo».

- «El dinero está para gastarlo».

El estudio evidencia un bajo conocimiento de conceptos financieros básicos, una significativa «falta de resiliencia» y preparación ante emergencias o shocks externos y, en consecuencia, un amplio margen de mejora en lo que a educación financiera se refiere (OCDE, 2020a). Así, construyendo un indicador global -como la suma de todos los indicadores anteriores-, obtiene una puntuación promedio, para el conjunto de los países encuestados, de 12,7 puntos frente a la puntuación máxima posible de 21 puntos (suma de 7 puntos de conocimiento, 9 de comportamiento y 5 de actitudes), según se puede observar en la figura 1.
Un reciente estudio de la OCDE concluye que la población adulta encuestada en 26 países del G20 evidencia un bajo conocimiento de conceptos básicos financieros, una significativa falta de resiliencia y preparación ante emergencias o shocks externos y, en consecuencia, un amplio margen de mejora en lo que a educación financiera se refiere. Así, construyendo un indicador global, obtiene una puntuación promedio, para el conjunto de los países encuestados, de 12,7 puntos frente a la puntuación máxima posible de 21 puntos 
Figura 1. Indicador global de educación financiera (como suma de conocimiento financiero, conductas y actitudes $)^{2}$

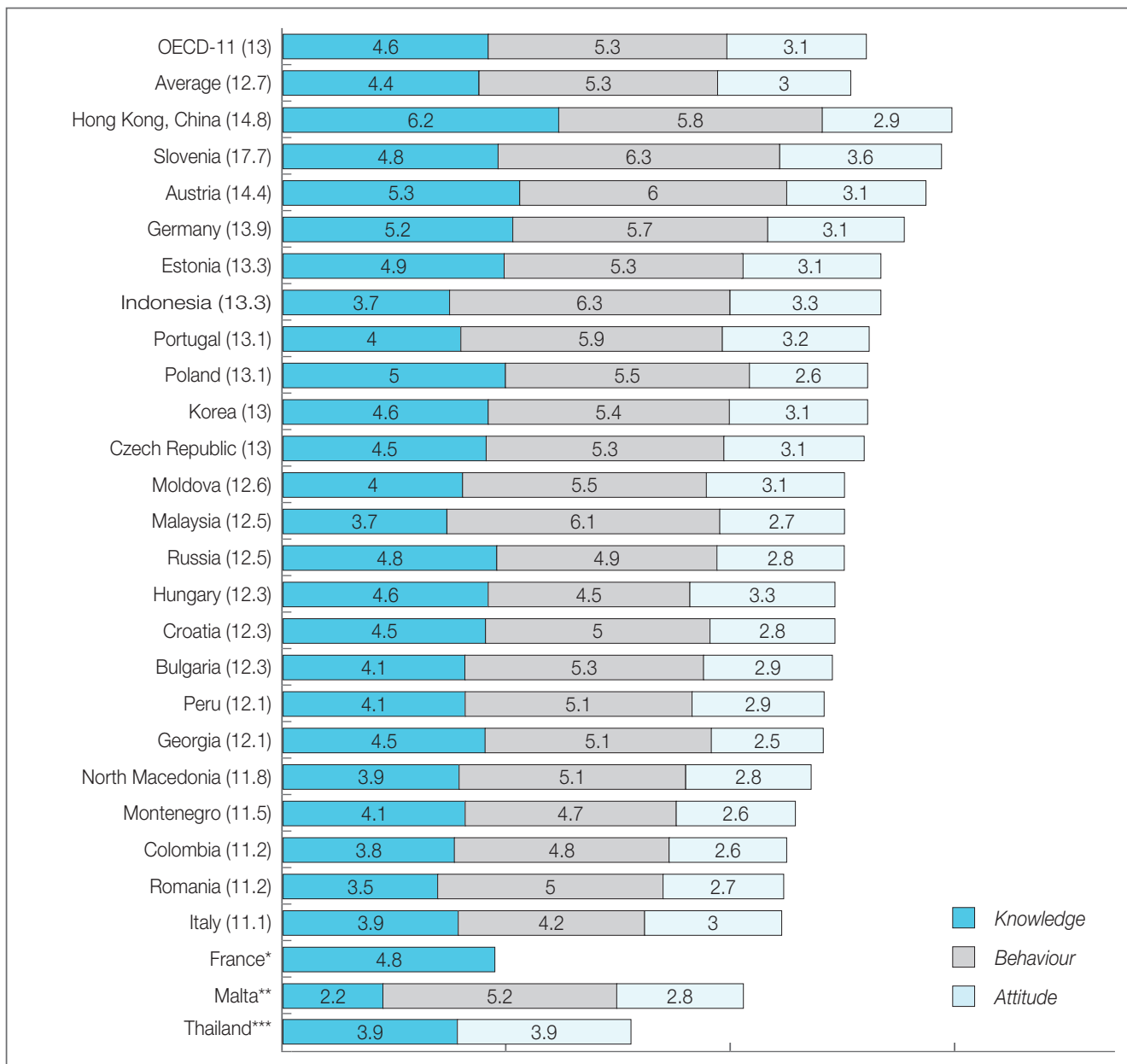

Note: Peru, attitude score. One of the three statements included in the financial attitude score for Peru uses different wording to assess long term attitude to money.

* France has gathered data only for financial knowledge in this round of data collection.

** Malta asked only 4 knowledge questions and 7 behaviour ones, so overall, knowledge and behaviour scores are not comparable. These scores are not comparable given that the Malta survey was carried out in between OECD's 2016 and 2018 survey cycles, hence the Malta survey research instrument was designed on a draft OECD questionnaire, which was not yet finalised. The next Malta survey is planned to sync with OECD's next survey cycle.

*** Thailand has used the 2015 OECD Toolkit and the behaviour score is thus not comparable. Averages exclude France, Malta and Thailand. The OECD-11 average includes the OECD member countries in the sample for which there is data, which are: Austria, Colombia, Czech Republic, Estonia, Germany, Hungary, Italy, Korea, Poland, Portugal and Slovenia.

Fuente: OCDE (2020a, p. 16).

2 Reproducimos la figura 1 íntegramente en inglés, tal cual aparece en el documento oficial de la OCDE (2020a), por no existir una traducción oficial en lengua española. 
La población joven no sale mejor parada. El último informe PISA (Programme for International Student Assessment) (OCDE, 2020b) sobre competencia financiera de estudiantes de 15 años, referido a datos de 2018, encuentra una puntuación media en cultura financiera de 505 puntos, considerando solo los países de la OCDE, y de 478 puntos, considerando el total de países participantes en la encuesta ${ }^{3}$. Estas puntuaciones equivalen a un nivel medio-bajo en competencia financiera, concretamente, a un nivel 3 sobre los cinco niveles definidos por el organismo internacional ${ }^{4}$.

Así pues, podría afirmarse que, en general, reina un «analfabetismo financiero» a nivel mundial (Lusardi y Mitchel, 2011). ¿Cambia la situación si consideramos el caso específico de España? Lo vemos en el apartado siguiente.

Podría afirmarse que, en general, reina un «analfabetismo financiero» a nivel mundial (Lusardi y Mitchel, 2011)

\subsection{Situación de la educación financiera en España}

En el caso de España, la Encuesta de Competencias Financieras (ECF) (Bover et al., 2016) es el estudio más completo que existe hasta la fecha sobre los conocimientos y las conductas financieras de los adultos en España (entre 18 y 79 años).

La ECF ha sido desarrollada por el Banco de España y la Comisión Nacional del Mercado de Valores (CNMV) en el marco del Plan de Educación Financiera (PEF), ha contado con la colaboración del Instituto Nacional de Estadística para asegurar la obtención de una muestra de adultos representativa de toda la población española y ha seguido la metodología que permite el cálculo de los indicadores propuestos por la OCDE (2017), comentados en el apartado anterior ${ }^{5}$. Los resultados muestran un bajo nivel de cultura financiera de la población adulta española.

Así, respecto a los conocimientos, solo algo más de la mitad de los españoles entrevistados (58\%) responde correctamente a una sencilla pregunta sobre el concepto de «inflación», un $46 \%$ a una pregunta sobre el concepto de «tipo de interés compuesto» y un $49 \%$ sobre el concepto de «diversificación del riesgo».

320 países y economías participaron en la encuesta: 13 de la OCDE (Australia, Canadá, Chile, Estonia, Finlandia, Italia, Letonia, Lituania, Polonia, Portugal, República Eslovena, España y EE. UU.) y 7 países colaboradores (China, Bulgaria, Georgia, Indonesia, Perú, Brasil, Rusia y Serbia).

4 Distinguen cinco niveles de competencia de mayor a menor puntuación: nivel 5 (625 puntos o más), nivel 4 (550-625), nivel 3 (475-550), nivel 2 (400-475) y nivel 1 (326-400).

5 Actualmente, en 2021, se está llevando a cabo la segunda edición de la ECF. 
Respecto a los comportamientos financieros, la ECF encuentra conductas destacables:

- Un $61 \%$ de los hogares ha ahorrado activamente en el último año por diversas vías, principalmente a través de su cuenta corriente (63\%), frente al $28 \%$ de los españoles que manifiesta vivir en hogares con desahorro, es decir, en hogares cuyos gastos han excedido a sus ingresos en los últimos 12 meses.

- Un $52 \%$ de los españoles reside en hogares que, de perder su fuente principal de renta, podrían mantener su gasto durante al menos seis meses sin endeudarse ni vender propiedades; un $8 \%$ podría mantener su gasto menos de un mes (y más de una semana) y un $7 \%$ de individuos podría mantener su gasto menos de una semana.

- Solo un 35 \% de la población española que adquirió algún producto financiero en los últimos dos años consideró para su contratación varias alternativas de empresas distintas, mientras que un $62 \%$ se limitó a comparar varias alternativas de una sola empresa o incluso no consideró ninguna otra opción.

En comparación con los países de la OCDE y de la Unión Europea, para los que hay datos disponibles, el nivel de conocimientos de la población adulta española se sitúa en torno a la media, si bien, en el concepto de «diversificación del riesgo», los españoles estamos «claramente por debajo de la media» (Bover et al., 2016, p. 59). En cuanto a la tenencia de productos financieros, los españoles nos situamos por encima de la media de todos los países considerados en la tenencia de una cuenta corriente, por debajo en la tenencia de productos de ahorro (cuentas de ahorro, planes de pensiones, fondos de inversión, acciones, renta fija y seguros de vida) y superamos la media de todos los países considerados en la tenencia de deudas (tarjetas de crédito, préstamos hipotecarios y personales). Si atendemos a la decisión de «desahorro», el porcentaje de individuos cuyos gastos han superado a sus ingresos durante el último año es similar a la media de los países de la OCDE y de la Unión Europea, si bien debe tenerse en cuenta que, en España, la ECF preguntó por los gastos e ingresos del «hogar», en lugar del «individuo», como hizo el estudio internacional (ibidem).

En relación con la población joven, el informe PISA para el caso de España en competencia financiera (OCDE, 2020b) encuentra que, en promedio, la puntuación obtenida por los estudiantes españoles -492 puntos- está por debajo de la media del resto de los países de la OCDE -505 puntos-, siendo esta diferencia estadísticamente significativa.

Los datos muestran, por tanto, que un grupo muy amplio de la población en España no está familiarizado con conceptos financieros básicos ni con actitudes y hábitos saludables hacia el dinero. Parece, pues, deseable emprender acciones específicas de formación financiera de alcance nacional. 
La Estrategia Nacional de Educación Financiera -materializada en el PEF- asume desde 2008 este cometido a través de un convenio de colaboración entre el Banco de España y la CNMV, y, muy recientemente -desde enero del 2021-, el Ministerio de Consumo. Esta estrategia se articula mediante sucesivos planes de actividades plurianuales (el último corresponde al periodo 2018-2021) y se apoya en una red de entidades colaboradoras públicas (entre ellas, la Dirección General de Seguros y Fondos de Pensiones y la Secretaría General del Tesoro y Financiación Internacional) y, principalmente, privadas sin ánimo de lucro, operantes en las áreas del consumo, del sector asegurador y del crédito o de la educación e investigación, entre otras. Su objetivo es llevar la educación financiera al máximo número de colectivos y sensibilidades sociales.

En el marco del PEF, y bajo la marca blanca «Finanzas Para Todos», se vienen desarrollando importantes iniciativas de alcance nacional, como el Programa Escolar de Educación Financiera, el portal web Finanzas Para Todos o el Día de la Educación Financiera (Banco de España y CNMV, 2018-2021), junto con diversas y variadas iniciativas por parte de sus colaboradores y de otras entidades privadas. Adicionalmente, el Banco de España y la CNMV ofrecen a los ciudadanos sendos portales de información para el cliente bancario y el inversor, respectivamente ${ }^{6}$.

\begin{abstract}
Los datos muestran que un grupo muy amplio de la población en España no está familiarizado con conceptos financieros básicos ni con actitudes y hábitos saludables hacia el dinero. [...] La Estrategia Nacional de Educación Financiera -materializada en el PEF-asume desde 2008 este cometido de formación financiera a través de un convenio de colaboración entre el Banco de España y la CNMV, y, muy recientemente - desde enero del 2021-, el Ministerio de Consumo
\end{abstract}

\section{El enfoque conductual}

La ciencia conductual es un campo de estudio que combina el análisis económico, psicológico y sociológico para estudiar el proceso de toma de decisiones de los individuos. Partiendo del concepto de «racionalidad limitada» de Simon $(1955)^{7}$, este enfoque considera un procedimiento de resolución de problemas y de toma de decisiones basado, en buena medida, en intuiciones y emociones, y dependiente de las circunstancias y el contexto. Kahneman (2003) distingue dos sistemas cognitivos neuronales:

6 Portal del Cliente Bancario (https://clientebancario.bde.es/pcb/es/), del que se hablará más adelante, y Portal del Inversor (http://www.cnmv.es/Portal/Inversor/Indice.aspx).

7 Según la teoría de la racionalidad limitada de Simon, la toma de decisiones no puede considerar todo el rango completo de alternativas, sino que tiene que separar problemas y centrar la atención en los prioritarios. Como consecuencia, las decisiones finalmente acometidas por los individuos no son necesariamente consistentes ni optimizadoras. 
- Sistema 1. Inconsciente, impulsivo, automático e intuitivo.

- Sistema 2. Caracterizado por un razonamiento consciente, deliberado y, por ello, más lento.

La ciencia conductual reconoce que ambos sistemas, el intuitivo y el razonado, se coordinan e interaccionan entre sí en la toma de decisiones humanas. De este modo, el comportamiento humano puede ser concebido en términos de procesos duales de emoción y deliberación (Baddeley, 2019).

\section{La ciencia conductual reconoce que ambos sistemas, el intuitivo y el razonado, se coordinan e interaccionan entre sí en la toma de decisiones humanas}

En el ámbito bancario, objeto de nuestro interés, las principales aportaciones del enfoque conductual son la consideración de heurísticas y sesgos en el proceso de toma de decisiones financieras y el desarrollo de evidencia experimental que sustenta una nueva caracterización del agente económico, alejada del tradicional homo economicus ${ }^{8}$.

\subsection{Heurísticas o atajos mentales}

Las heurísticas son reglas o atajos mentales que utilizamos de manera natural para tomar decisiones inmediatas en entornos de incertidumbre (Baddeley, 2019). Tversky y Kahneman (1974) señalan tres heurísticas principales para valorar la probabilidad de eventos inciertos:

- Representatividad. Según esta heurística, las personas valoramos las probabilidades de que ocurra un suceso por analogía a estereotipos. Por ejemplo, si tenemos que asignar probabilidades a la ocupación profesional de Juan, de entre una serie de ocupaciones posibles (granjero, comercial, piloto, bibliotecario o físico), y nos dan el dato de que «Juan es introvertido y minucioso», en la medida en que esta información sea representativa del estereotipo que tenemos de un bibliotecario, asignaremos una mayor probabilidad a que la ocupación de Juan sea la de bibliotecario.

- Disponibilidad. En virtud de esta heurística, los eventos que más rápidamente nos vienen a la mente (los «más disponibles») son los que juzgamos como los más numerosos y probables de ocurrir. Los eventos más disponibles son los que recordamos más fácilmente por su carácter reciente, por resultarnos más familiares

8 En la teoría económica neoclásica, el homo economicus es la modelización de un agente económico representativo «racional», caracterizado por tener preferencias estables a lo largo del tiempo, maximizar su utilidad y ser esencialmente egocéntrico en sus decisiones (Van Raaij, 2016). 
o por haber provocado en nosotros un mayor impacto emocional. Por ejemplo, si vemos un coche volcado en la carretera, aumentaremos temporalmente nuestra probabilidad de sufrir un accidente.

- Anclaje y ajuste. En muchas situaciones, tomamos decisiones en función de una primera estimación o punto de partida que sirve de ancla o referencia, que se va ajustando, a la luz de nueva información, respecto al valor inicial. Un experimento que ilustra el efecto anclaje pidió a distintos grupos de individuos que estimaran el porcentaje de países africanos que forman parte de las Naciones Unidas, dándoles a cada grupo puntos de partida iniciales de manera aleatoria. Así, los grupos que recibieron el número 10 como punto de partida estimaron este porcentaje en un $25 \%$, frente a los grupos que recibieron un 65 como punto de partida, que establecieron el porcentaje de países africanos en el $45 \%$.

Las heurísticas nos ayudan a tomar decisiones «razonables» utilizando la mínima información posible y el sentido común. Sin embargo, decisiones razonables no significan necesariamente «las mejores decisiones» y pueden verse afectadas por errores sistemáticos o «sesgos cognitivos» (Baddeley, 2019).

\subsection{Sesgos cognitivos}

Un sesgo cognitivo es un error sistemático (no aleatorio) en el razonamiento y en la toma de decisiones humanas, entre las que se incluyen las de índole financiero. La literatura recoge evidencia de múltiples sesgos cognitivos que están, además, fuertemente relacionados entre sí. Muy sucintamente, y sin ánimo exhaustivo, los sesgos en el ámbito bancario más estudiados en la literatura son los siguientes:

- Sesgo por el presente. Frente a dos momentos futuros, concedemos un mayor peso relativo al momento temporalmente más próximo (O’Donoghue y Rabin, 1999). Este sesgo se traduce en una desproporcionada preferencia por la inmediatez del presente y explicaría, por ejemplo, la evidencia encontrada de un insuficiente nivel de ahorro entre la población para la etapa de la jubilación (Hershfield et al., 2011).

Teniendo en cuenta el sesgo por el presente, las medidas que la literatura especializada propone para compensar esta tendencia son:

- Comprometer por anticipado una parte de nuestros ingresos futuros a través, por ejemplo, de un plan de jubilación.

- Incrementar el atractivo por la paciencia, comprendiendo las consecuencias positivas de esperar y los usos futuros que le podremos dar a nuestro dinero si somos pacientes. 
- Interaccionar con nuestra propia imagen futura -envejecida-, mediante el uso de la tecnología de la realidad virtual, para destinar más recursos al futuro (Hershfield et al., 2011).

- Aversión a la pérdida. Las personas valoramos más las pérdidas potenciales que las ganancias potenciales (Kaheman y Tversky, 1979) o, dicho de otra manera, perder lo que ya tenemos nos disgusta más que ganar lo que aún no tenemos. Según Thaler (1999), la aversión a la pérdida nos lleva a realizar una «edición hedónica» de nuestras pérdidas y ganancias, de tal forma que tendemos a agrupar las pérdidas, segregar las ganancias, integrar pequeñas pérdidas con grandes ganancias y extraer pequeñas ganancias de grandes pérdidas.

Un ejemplo de este comportamiento lo encontramos en el pago mediante tarjeta de crédito: a la hora de la liquidación, nos llegan de una vez todos los cargos del mes, de modo que una amalgama de muchos pagos por distintos conceptos reduce el impacto y el dolor que nos produciría pagar cada uno de ellos por separado (Ariely y Kreisler, 2018). Además, el pago mediante tarjeta de crédito reúne otras dos características que reducen el dolor de pagar (ibidem):

- Separa temporalmente la compra del pago.

- Nos hace ser menos conscientes del acto de pagar con un simple acercamiento del plástico o el dispositivo móvil al TPV (terminal punto de venta), en lugar de tener que rebuscar en nuestro monedero el dinero necesario para realizar el pago.

Esto explicaría la evidencia encontrada por Soman (2001) de que los consumidores gastan más cuando pagan con tarjeta de crédito que cuando lo hacen en efectivo.

- Sesgo del statu quo. Se refiere a nuestra tendencia a mantener las decisiones que ya tomamos en su día ante la aparición de nuevas alternativas y a «optar por no hacer nada» (Samuelson y Zeckhauser, 1988). Las razones de este comportamiento son la aversión a la pérdida y el efecto anclaje: considerando el statu quo como el punto de referencia de nuestras decisiones y, dado que, por la aversión a la pérdida, valoramos más las potenciales pérdidas que las potenciales ganancias, entonces elegimos quedarnos como estamos (ibidem).

Esto se reforzaría por la aparición de una suerte de «compromiso psicológico con la alternativa statu quo», derivado de la existencia de los llamados «costes sumergidos" (sunk costs) y de ciertos factores psicológicos. Respecto a los primeros, y en la medida en que nuestra elección inicial haya conllevado una gran inversión de recursos irrecuperables (costes sumergidos), nos mantendremos en ella. Por ejemplo, esta circunstancia se encuentra en decisiones políticas que conllevan fuertes inversiones iniciales (como la construcción y el mantenimiento de un aeropuerto que resulta ser deficitario), en la esperanza -vana- de recuperar 
costes algún día. Adicionalmente, otros factores psicológicos que explicarían el sesgo del statu quo son la «aversión al arrepentimiento» -para evitar poder arrepentirnos de una mala decisión, preferimos no arriesgar y quedarnos como estamos- y el «sesgo de confirmación» -en la necesidad de justificar decisiones pasadas, nos mantenemos en ellas-.

Entre los diversos ámbitos donde el statu quo opera, estos autores mencionan el de las decisiones de consumo, materializado en la ausencia o insuficiente búsqueda por parte de los consumidores de alternativas de consumo a mejores precios. En esta línea, la Autoridad de Conducta Financiera del Reino Unido (Financial Conduct Authority [FCA]) encontró evidencia del statu quo en el mantenimiento de las cuentas corrientes de los clientes bancarios (consumidores y pymes), con una tasa muy alta de los mismos (un $89 \%$ ) que no cambió de cuenta ni consideró dicha posibilidad en los últimos 12 meses (Fincham et al., 2015). Frente al sesgo del statu quo, «no parece que existan vías obvias que lo eviten, más allá de apelar a los individuos a sopesar equitativamente todas las opciones cuando tomen sus decisiones» (Samuelson y Zeckhauser, 1988, p. 9).

- Efecto marco. El modo de presentar una elección condiciona los resultados (Tversky y Kahneman, 1981). Este sesgo es ampliamente estudiado y puesto en práctica en el ámbito del marketing para influir en las decisiones de consumo. Existe evidencia de que factores como los siguientes afectan a nuestras percepciones y elecciones sobre los productos, en combinación con las heurísticas comentadas de representatividad, anclaje y disponibilidad (Richard y Yong, 2000): orden de presentación de los mensajes, credibilidad de la fuente de la que proceden, planteamiento de la información, por ejemplo, en términos positivos (de ganancias) o negativos (de pérdidas), el contexto en el que se presenta el mensaje, incluidas las asociaciones verbales o las circunstancias y modas sociales o los atributos del comunicador del mensaje y las asociaciones mentales que provoca en nosotros.

La publicidad de los productos bancarios también trata de explotar el efecto marco con fines comerciales. Así, por ejemplo, pueden encontrarse anuncios que resaltan la información de «financiación sin intereses», refiriéndose a un interés nominal nulo, a pesar de que la financiación presente una tasa anual equivalente (TAE) positiva (quizá recogida en letra pequeña), al conllevar algún tipo de comisión o gasto adicional. La financiación para la adquisición de un vehículo también puede encontrarse planteada de un modo «excesivamente positivo», por ejemplo, presentando un «precio al contado del vehículo» superior al «precio sujeto a la financiación», al no incluir, este último, los importes correspondientes a la entrada inicial y la comisión de apertura? ${ }^{9}$.

9 Véase la publicación «¿En qué te fijas al comprar un coche? ¡No minusvalores la financiación!» dentro del Portal del Cliente Bancario del Banco de España (https://clientebancario.bde.es/pcb/es/blog/En_ que_te_fija_58776d6cab82961.html). En aras de la protección del cliente bancario, existe una normativa 
La creciente digitalización del mercado financiero puede agravar los efectos de estos sesgos (OCDE, 2017) como consecuencia de la fácil y rápida accesibilidad de los usuarios a determinados productos bancarios (¡contratación con un solo clic!). La educación financiera de los usuarios bancarios se hace más necesaria en el entorno digital y el enfoque conductual puede contribuir a ello. En el apartado siguiente vemos cómo.

\subsection{Las aplicaciones del enfoque conductual en la educación financiera}

La aplicación de los descubrimientos de la ciencia conductual en el diseño de iniciativas de educación financiera es una tarea en incipiente desarrollo. Un reciente documento de la Red Internacional de Educación Financiera de la OCDE (International Network on Financial Education (INFE) (OCDE, 2019) presenta algunas indicaciones clave para ello.

Según este documento, las intervenciones en materia de educación financiera deben dirigirse principalmente a cambiar el contexto para animar a los ciudadanos a tomar mejores decisiones financieras y a elegir comportamientos más apropiados, siempre respetando su libertad, así como a informar a los consumidores sobre los sesgos típicos que se producen en la toma de decisiones financieras, proporcionándoles estrategias mentales para evitar sus posibles efectos negativos. Concretamente, recomiendan cinco aplicaciones específicas para el diseño de iniciativas de educación financiera (OCDE, 2019):

- Desarrollo de contenido concentrado, directo y sencillo de entender. Se recomienda proporcionar información corta -a modo de «píldoras de conocimiento»y apropiada según el público objetivo; proponer reglas fáciles de recordar (simples, resumidas, directas) para los asuntos financieros cotidianos; cuidar el «envoltorio» del mensaje mediante la utilización de palabras adecuadas, un tono positivo e imágenes atractivas; y presentar adecuadamente la información relevante, ofreciendo las cifras más significativas en un orden y posición adecuadas, utilizando puntos o guiones en la exposición de la información, simplificando textos e incluyendo frases específicas para enfatizar ideas.

- Diseño de programas de educación financiera personalizados. Se recomienda personalizar al máximo las iniciativas de educación financiera con el fin de lograr

aplicable a la publicidad de productos financieros que establece el contenido mínimo y el formato del mensaje publicitario para que la información proporcionada sea clara, suficiente, objetiva y no engañosa (concretamente, la Circular del Banco de España 6/2010, de 28 de septiembre, a entidades de crédito y entidades de pago, sobre publicidad de los servicios y productos bancarios; la Orden ECC/2316/2015, de 4 de noviembre, relativa a las obligaciones de información y clasificación de productos financieros; y la Orden EHA/1718/2010, de 11 de junio, de regulación y control de la publicidad de los servicios y productos bancarios). 
un mayor compromiso y fidelidad del público objetivo. Así, se propone el diseño de programas basados en la vida real (con casos prácticos e historias personales), considerando el momento vital adecuado para proporcionar la información (por ejemplo, a los que se vayan a hipotecar por vez primera), ofreciendo consejos individualizados y herramientas que ayuden a los consumidores a comprender los principales sesgos que pueden afectar a sus decisiones, todo ello con una actitud positiva hacia las finanzas.

- Ir más allá de la información, ayudando a la ciudadanía a emprender acciones. Se propone diseñar iniciativas interactivas y ofrecer herramientas que posibiliten un mejor autocontrol (por ejemplo, a través de la herramienta del presupuesto personal) o que permitan poner en práctica las habilidades aprendidas (por ejemplo, a través de juegos online o simuladores). Los principios de la gamificación pueden ser aplicados también a la educación financiera a través de retos, premios o concursos, entre otras técnicas.

- Uso de canales digitales. Se recomienda el desarrollo de páginas web, aplicaciones móviles, simuladores, así como la puesta en marcha de canales fácilmente accesibles, atractivos y entretenidos. Por ejemplo, se hace hincapié en el poder de las imágenes y los efectos visuales.

- Consideración de metodologías y marcos de conducta para el diseño de programas de educación financiera. Se apuesta por aumentar el conocimiento sobre los modelos y marcos conductuales existentes y tomarlos como guía para el desarrollo de recursos, iniciativas y programas de educación financiera.

La enseñanza que se desprende del enfoque conductual es que la educación financiera de la ciudadanía debe considerar las heurísticas y los sesgos de comportamiento más comunes y facilitar que los usuarios bancarios interpreten correctamente la información disponible. De esta manera se podrán mover, eventualmente, las conductas de los ciudadanos hacia comportamientos financieros más saludables (Campbell et al., 2011; OCDE, 2017).
La educación financiera debe considerar las heurísticas y los sesgos de comportamiento más comunes para facilitar que la ciudadanía interprete correctamente la información bancaria disponible

En este cometido, las herramientas digitales pueden tener un papel notable para ser utilizadas en la promoción de conductas como, por ejemplo, utilizar un presupuesto, comparar precios y ofertas a la hora de contratar productos, pagar regularmente los recibos o recurrir al crédito de manera responsable (OCDE, 2017). La iniciativa educativa emprendida, descrita a continuación, utilizó el Portal del Cliente Bancario para materializar las cinco recomendaciones apuntadas por la OCDE en una propuesta práctica. 


\section{De la teoría a la práctica: series de contenidos para la edu- cación financiera}

Teniendo en cuenta las recomendaciones de la OCDE y las consideraciones conductuales expuestas en los apartados anteriores, se decidió pasar de la teoría a la práctica. Para ello, se idearon y elaboraron (por parte de quien suscribe estas líneas) dos series de contenidos en el Portal del Cliente Bancario del Banco de España, a modo de «píldoras de conocimiento", con el fin de estimular el interés de los ciudadanos por sus finanzas personales y contribuir a su educación financiera:

- «Jeroglíficos Financieros». Esta serie planteaba semanalmente un jeroglífico sobre algún concepto financiero básico.

- "Decisiones con Cabeza». Esta otra serie informaba mensualmente sobre algunos de los sesgos típicos que se producen en la toma de decisiones bancarias, proponiendo estrategias y herramientas concretas para su control y minimización.

Ambas series fueron publicadas en el segundo semestre de 2019 y están disponibles en la sección «Blog» ${ }^{10}$ del citado portal del Banco de España.

\subsection{El Portal del Cliente Bancario}

Se trata de un portal de internet del Banco de España dedicado a los clientes bancarios para orientarles en sus relaciones con los bancos y facilitar su información y educación financiera. Disponible también en lengua inglesa, actualmente el Portal del Cliente Bancario se estructura en torno a cuatro secciones, tres de ellas con contenidos fijos:

- Productos y Servicios Bancarios. Informa sobre sus principales características.

- Podemos Ayudarte. Ofrece herramientas, simuladores y respuestas a consultas bancarias habituales.

- Educación Financiera. Describe las acciones emprendidas en este campo.

- Blog. De contenidos semanales.

10 Serie «Jeroglíficos Financieros» (https://app.bde.es/atz_www/jsp/webSearch.jsp?idioma=es\&acceso=p cb\&tipo=avanzado\&T6=pcb\&T3=Todos\&T1=jerogl\%C3\%ADficos+financieros+2019) y serie $«$ Decisiones con Cabeza» (https://app.bde.es/atz_www/jsp/webSearch.jsp?idioma=es\&acceso=pcb\&tipo=avanzado \&busnormal=Buscar\&T6=pcb\&T3=Todos\&T1=\%22poner+cabeza\%22). 
Los contenidos de la sección «Blog» se publican en forma de artículos cortos (o posts) y abordan temas sobre la práctica bancaria habitual especialmente significativos para los ciudadanos por su interés y actualidad. Debido a su naturaleza dinámica y cercana al gran público, esta sección «Blog» recibe una especial atención por parte del Comité de Redacción del Portal del Cliente Bancario, que se esfuerza por ofrecer textos sencillos y claros. Además, se elige, para cada uno de los posts, una imagen atractiva y simpática que estimule al lector -público adulto, generalmente- a leer su contenido.

En 2020, el Portal del Cliente Bancario recibió un total de 5.490.379 visitas (Departamento de Conducta de Entidades [DCE], 2020). Durante este último año, las secciones más visitadas fueron las correspondientes a los simuladores (recibiendo 834.479 visitas) y los tipos de interés (231.830), seguidas de los contenidos publicados en el «Blog» (más de 170.000 visitas), destacando los de carácter práctico y aplicado, como «Cómo cobrar un cheque» o «Qué hacer cuando fallece el titular de una cuenta bancaria» (DCE, 2019).

\subsection{Serie «Jeroglíficos Financieros»}

Esta serie se publicó en los meses de julio y agosto de 2019, aprovechando el periodo vacacional estival. Se concibió como una iniciativa creativa de gamificación de la educación financiera dirigida al público adulto, más familiarizado que el joven con los pasatiempos veraniegos tradicionales. En ella se planteaba semanalmente un jeroglífico sobre algún concepto financiero básico y se remitía al lector a una pista en forma de hipervínculo a algún contenido del portal relacionado con su solución, la cual se desvelaba en el jeroglífico de la semana siguiente. Se pretendió, de este modo, estimular al usuario a leer otros contenidos del Portal del Cliente Bancario para resolver el acertijo y poner a prueba su ingenio y sus conocimientos financieros de manera divertida. El cuadro 1 recoge la planificación cronológica de la serie «Jeroglíficos Financieros».

Cuadro 1. Planificación de la serie "Jeroglíficos Financieros»

Orden Conceptos financieros relacionados con la solución (y enlace al jeroglífico)

Cancelación de un préstamo:

https://clientebancario.bde.es/pcb/es/blog/jeroglificos-financieros-2019--1-.html

2

Comisión por descubierto y tipos de comisiones:

https://clientebancario.bde.es/pcb/es/blog/jeroglificos_financieros_2019_2.html

Cambio de condiciones en el contrato de productos bancarios:

https://clientebancario.bde.es/pcb/es/blog/jeroglificos-financieros-2019--3-.html 


\section{Orden \\ Conceptos financieros relacionados con la solución (y enlace al jeroglífico)}

4

Tarjeta bancaria y qué hacer si me roban o clonan la tarjeta:

https://clientebancario.bde.es/pcb/es/blog/jeroglificos_financieros_2019_4.html

5

La TAE y la publicidad de productos bancarios:

https://clientebancario.bde.es/pcb/es/blog/jeroglificos-financieros-2019--5-.html

6

Préstamo personal y crédito al consumo:

https://clientebancario.bde.es/pcb/es/blog/jeroglificos-financieros-2019--6-.html

Fuente: elaboración propia

\section{«Pantallazos» de la serie «Jeroglíficos Financieros» publicada en el Portal del Cliente Bancario}

Llega el verano y con él nuestra sección de "Jeroglíficos Financieros» para poner a prueba tu ingenio y tus conocimientos financieros. La semana que viene te plantearemos un nuevo jeroglífico y te descubriremos la solución de este.

¡A ver si lo adivinas!

Te dejamos una pista por si la necesitas para dar con la solución.

\section{Jeroglíficos financieros 2019 (1)}

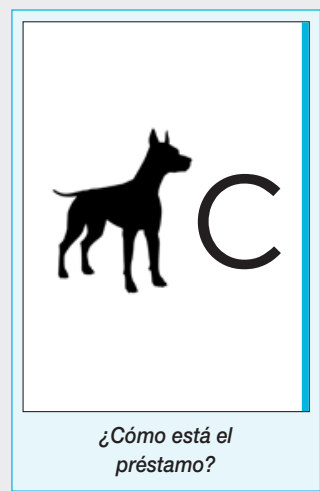

Fuente: https://clientebancario.bde.es/pcb/es/blog/jeroglificos-financieros-2019--1-.html

\section{$31 / 07 / 2019$}

Jeroglífico de la semana pasada. Solución: cancelado.

¿Lo adivinaste? 
¡Aquí te planteamos otro y te dejamos una pista por si la necesitas para dar con la solución!

Jeroglíficos financieros 2019 (2)

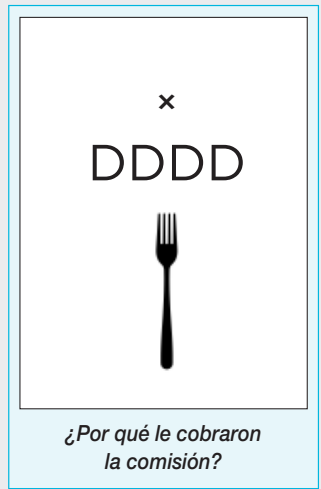

Fuente: https://clientebancario.bde.es/pcb/es/blog/jeroglificos_financieros_2019_2.html

\section{9/08/2019}

Jeroglífico de la semana pasada. Solución: por descubierto.

¿Lo adivinaste?

¡Aquí te planteamos otro y te dejamos una pista por si la necesitas para dar con la solución!

Jeroglíficos financieros 2019 (3)

\begin{tabular}{|l|}
\hline CONDICIONES \\
CONDICIONES \\
CONDICIONES \\
CONDICIONES \\
CONDICIONES \\
\hline ¿Qué te notificó el banco \\
sobre el contrato de cuenta?
\end{tabular}

Fuente: https://clientebancario.bde.es/pcb/es/blog/jeroglificos-financieros-2019--3-.html

$13 / 08 / 2019$

Jeroglííco de la semana pasada. Solución: un cambio de condiciones.

¿Lo adivinaste? 
¡Aquí te planteamos otro y te dejamos una pista por si la necesitas para dar con la solución!

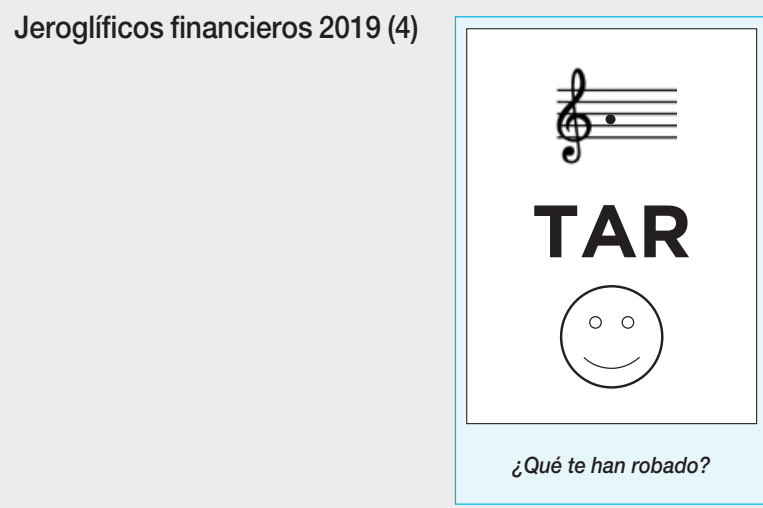

Fuente: https://clientebancario.bde.es/pcb/es/blog/jeroglificos_financieros_2019_4.html

\section{0/08/2019}

Jeroglífico de la semana pasada. Solución: la tarjeta.

¿Lo adivinaste?

¡Aquí te planteamos otro y te dejamos una pista por si la necesitas para dar con la solución!

Jeroglíficos financieros 2019 (5)

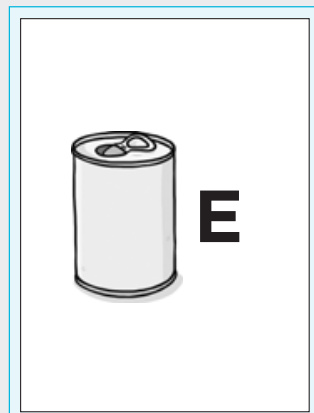

¿Qué te hizo decidirte por este préstamo?

Fuente: https://clientebancario.bde.es/pcb/es/blog/jeroglificos-financieros-2019--5-.html

\section{$27 / 08 / 2019$}

Jeroglífico de la semana pasada. Solución: la TAE. 
¿Lo adivinaste?

¡Aquí te planteamos otro y te dejamos una pista por si la necesitas para dar con la solución!

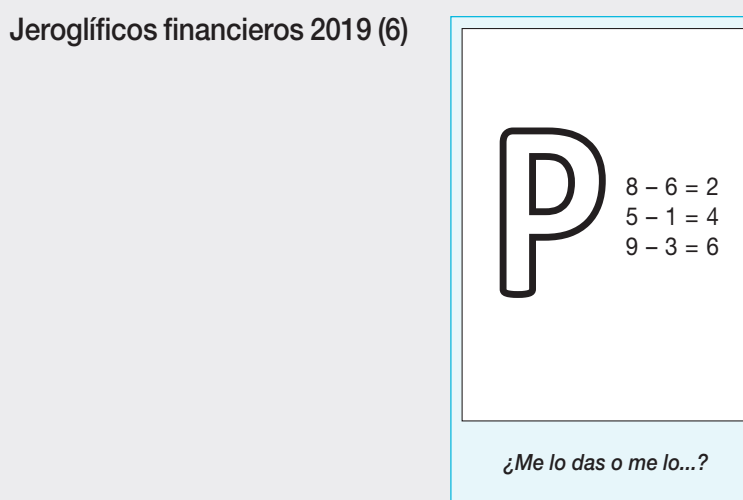

Fuente: https://clientebancario.bde.es/pcb/es/blog/jeroglificos-financieros-2019--6-.html

Finalizamos hoy la temporada de los jeroglíficos financieros, así que te dejamos abajo la solución de este último. Esperamos que te haya gustado esta sección veraniega.

Solución: prestas.

\subsection{Serie «Decisiones con Cabeza»}

Esta serie de posts se publicó entre los meses de septiembre y diciembre de 2019. En ella se abordaba cada vez un sesgo distinto en relación con alguna práctica habitual en el contexto bancario y se ofrecían estrategias concretas para contrarrestar sus efectos negativos, según refleja el cuadro 2. Los posts están redactados de una manera amena y sencilla y van acompañados de una imagen atractiva, así como de hipervínculos a diversos recursos digitales (calculadoras, simuladores, etc.) y a otros posts del Portal del Cliente Bancario relacionados. El citado cuadro recoge su planificación cronológica. Se pretendió con ello informar a los consumidores sobre los sesgos típicos que se producen en la toma de decisiones bancarias a través de pequeñas píldoras de conocimiento y dotarlos de recursos para su gestión adecuada.

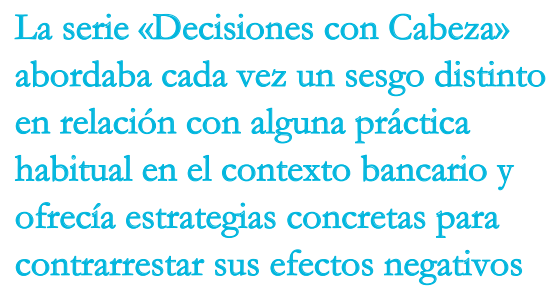

La serie «Decisiones con Cabeza» abordaba cada vez un sesgo distinto en relación con alguna práctica habitual en el contexto bancario y ofrecía estrategias concretas para contrarrestar sus efectos negativos 


\section{Cuadro 2. Planificación de la serie «Decisiones con Cabeza»}

\begin{tabular}{|c|c|c|c|}
\hline $\begin{array}{l}\text { Fecha de } \\
\text { publicación }\end{array}$ & $\begin{array}{l}\text { Sesgo típico } \\
\text { abordado }\end{array}$ & $\begin{array}{l}\text { Práctica financiera- } \\
\text { bancaria relacionada }\end{array}$ & Estrategias propuestas \\
\hline 04/09/2019 & $\begin{array}{l}\text { Post de presentación } \\
\text { de la serie. }\end{array}$ & & \\
\hline 09/09/2019 & Sesgo por el presente. & $\begin{array}{l}\text { Ahorro a largo plazo (jubi- } \\
\text { lación). }\end{array}$ & $\begin{array}{l}\text { Establecimiento de un porcentaje fijo } \\
\text { para destinar al ahorro. } \\
\text { Simulador de renta en la etapa de la jubi- } \\
\text { lación de «Finanzas para Todos». } \\
\text { Uso de alguna aplicación para envejecer. }\end{array}$ \\
\hline $11 / 10 / 2019$ & Sesgo statu quo. & $\begin{array}{l}\text { Cambio de condiciones } \\
\text { de la cuenta corriente. }\end{array}$ & $\begin{array}{l}\text { Comparador de comisiones e intereses } \\
\text { del Banco de España. } \\
\text { Estar pendiente de las notificaciones del } \\
\text { banco. }\end{array}$ \\
\hline $21 / 11 / 2019$ & Aversión a la pérdida. & $\begin{array}{l}\text { Pago con tarjeta de crédi- } \\
\text { to y decisiones de gasto. }\end{array}$ & $\begin{array}{l}\text { Establecimiento de un límite de crédito. } \\
\text { Combinación de distintos medios de } \\
\text { pago. }\end{array}$ \\
\hline $17 / 12 / 2019$ & Efecto marco. & $\begin{array}{l}\text { Publicidad de productos } \\
\text { bancarios. }\end{array}$ & $\begin{array}{l}\text { Calculadora de la TAE del Portal del } \\
\text { Cliente Bancario. }\end{array}$ \\
\hline
\end{tabular}

Fuente: Andújar (2019).

\section{Pantallazos de la serie «Decisiones con Cabeza» publicada en el Portal del Cliente Bancario}

\section{¿Decides con cabeza en tus finanzas?}

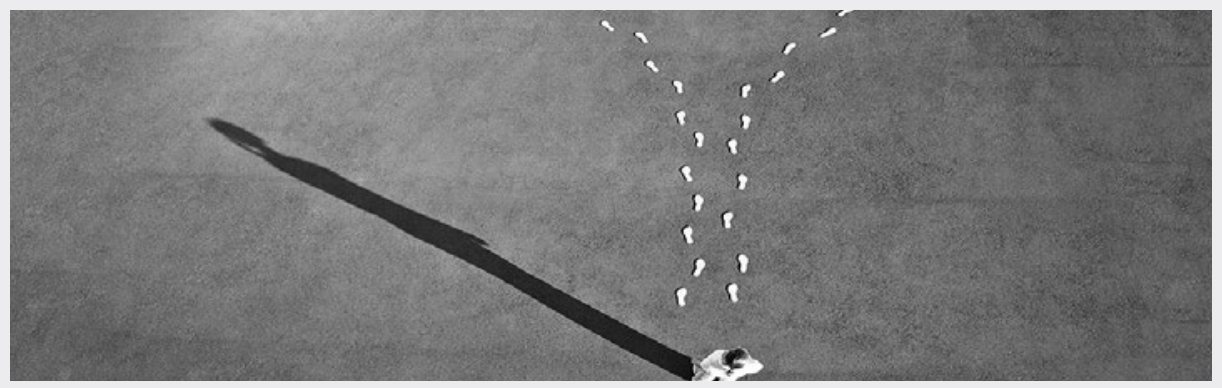

Fuente: https://clientebancario.bde.es/pcb/es/blog/decides-con-cabeza-en-tus-finanzas.html 
04/09/2019

La serie de posts «Decisiones con Cabeza» arrancará próximamente y nos descubrirá los procedimientos y errores más comunes en los que incurrimos a la hora de tomar decisiones financieras, en función de las investigaciones de la emergente disciplina de la economía de la conducta.

Siendo conscientes de estas tendencias y de los sesgos, podremos tratar de controlarlos y minimizarlos, en la medida de lo posible, mediante estrategias concretas que te ofreceremos para poner cabeza en tus finanzas y tomar unas mejores decisiones.

¡Sigue la serie «Decisiones con Cabeza»!

\section{«Vencer» al presente y ahorrar para la jubilación}

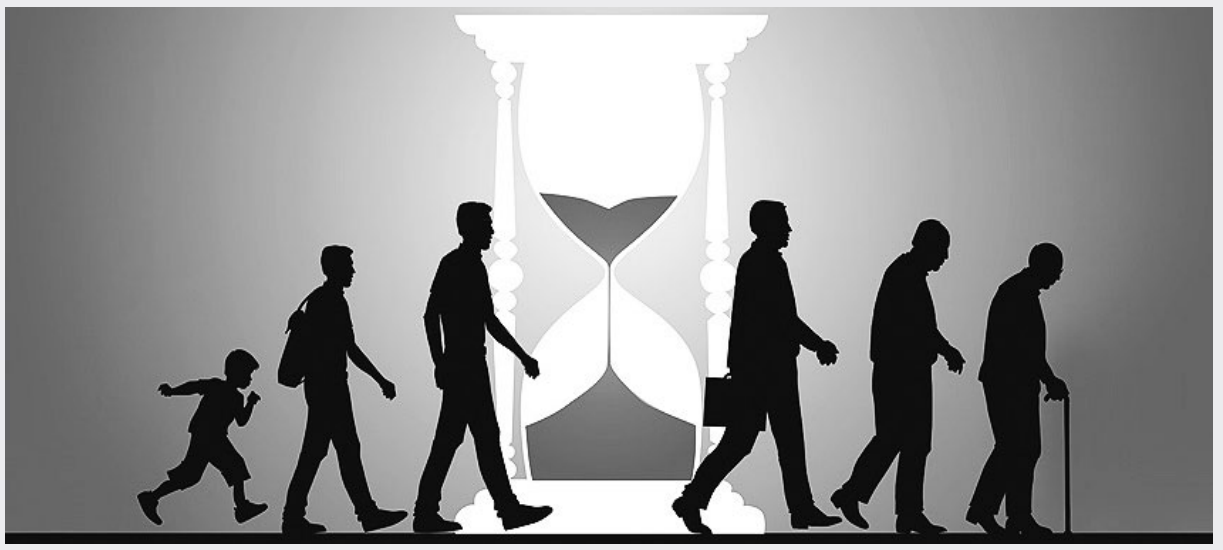

Fuente: https://clientebancario.bde.es/pcb/es/blog/sesgo-presente.html

\section{9/09/2019}

¿Te imaginas a ti mismo con 65 o 70 años? Probablemente, si te proyectas en el tiempo, pienses en ti mismo prácticamente como «un desconocido». Es una consecuencia del sesgo por el presente al que todos tendemos y que nos lleva a minusvalorar los resultados futuros y a preferir la inmediatez del momento presente.

Un sencillo ejemplo del sesgo por el presente podría ser tu propia respuesta a esta pregunta: ¿qué preferirías, que te dieran hoy mismo 100 euros o que te dieran 110 euros dentro de un año? Muy probablemente, elegirías la primera opción, aunque, si te paras a pensarlo, la segunda implica una remuneración del... ¡10\% anual!

Volviendo a «nuestros años de jubilación», es probable que, cuando llegue este momento, nuestros ingresos sufran una disminución que necesite ser compensada con algunos ahorros para poder mantener nuestra calidad de vida. El aumento de la longevidad hace conveniente tener que ahorrar, en la medida de lo posible, para esta importante -y, quizá, larga- etapa de nuestra vida. 
Puede que todavía quede mucho tiempo para que esto suceda. ¡Qué lejana puede ser para nosotros aún la idea de la jubilación! Pero es importante tenerla presente. ¡Es una realidad que, más pronto o más tarde, va a llegar y para la que tenemos que estar preparados!

Frente al sesgo por el presente, te proponemos estas tres estrategias para «poner cabeza» en tus decisiones de ahorro a largo plazo:

- Establece un porcentaje fijo de tus ingresos mensuales para destinarlos al ahorro para tu jubilación. Por ejemplo, si fijas una transferencia automática para apartar de tu nómina una pequeña cantidad todos los meses, podrás ir constituyendo poco a poco un fondo para tu jubilación, casi sin darte cuenta.

- Utiliza este simulador (abre en ventana nueva) para calcular la renta de la que podrás disfrutar en tu etapa de jubilación si comienzas a ahorrar hoy mismo.

- Proyéctate en el futuro y visualízate a ti mismo con unos cuantos años más (jactualmente es fácil encontrar aplicaciones para ello!). Seguramente, ver tu propia imagen envejecida te ayudará a superar el sesgo por el presente.

Referencia: Hershfield, H. E., Goldstein, D. G., Sharpe, W. F., Fox, J., Yeykelis, L., Carstensen, L. L. y Bailenson, N. J. (2011). Increasing saving behaviour through age-progressed renderings of the future self. Journal of Marketing Research, 48, Special Interdisciplinary Issue 2011: Consumer Financial Decision Making (2011): S23-S37.

¿Optas por no hacer nada ante un cambio de condiciones?

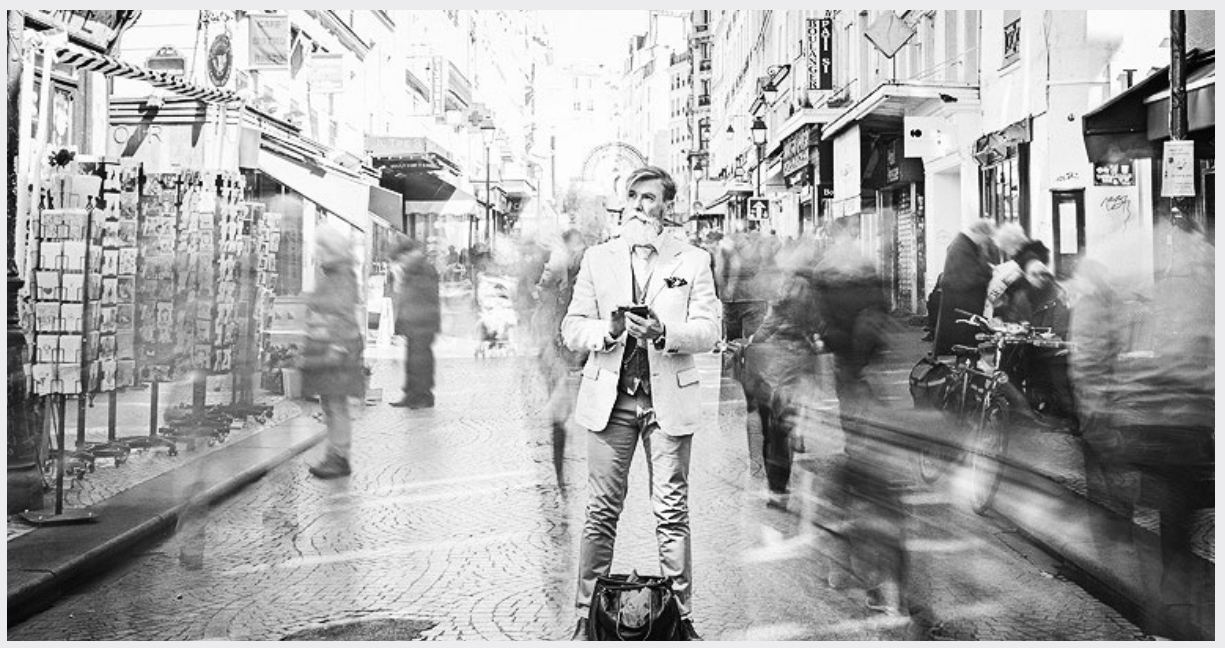

Fuente: https://clientebancario.bde.es/pcb/es/blog/optas-por-no-hacer-nada-ante-un-cambio-de-condiciones-.html 
$11 / 10 / 2019$

Es el llamado sesgo del statu quo: nuestra tendencia a quedarnos como estamos y a mantener las decisiones que ya tomamos en su día ante la aparición de cambios y alternativas. Es la decisión de no hacer nada. Sabemos que las entidades financieras pueden modificar unilateralmente las condiciones originales de nuestro contrato de cuenta y, por ejemplo, introducir nuevas comisiones siempre que nos lo comuniquen con una antelación mínima de dos meses. Si, ante esta notificación, nosotros optamos por no hacer nada, se entiende que aceptamos tácitamente las nuevas condiciones. De esto estamos hablando cuando nos referimos al sesgo del statu quo.

Sin embargo, tenemos en nuestras manos, además, otras opciones, como, en el caso del ejemplo, hablar con nuestro banco para negociar las nuevas condiciones o trasladar la cuenta a otra entidad bancaria que nos ofrezca otras mejores (bajo la nueva normativa, el traslado de cuenta es bien sencillo y gratuito).

Frente al sesgo del statu quo y a nuestra tendencia a quedarnos como estamos, te proponemos estas dos estrategias para poner cabeza ante un cambio en las condiciones de tus productos financieros:

- Estrategia 1. Utiliza este comparador de tipos y comisiones (abre en ventana nueva) del Banco de España para poder contrastar las comisiones y tipos que aplican las diferentes entidades y poder escoger la mejor opción para ti. El uso de este comparador también te permitirá ahorrar tiempo.

- Estrategia 2. Estate alerta a las notificaciones de tu banco. Recuerda que deberás revisar periódicamente el buzón electrónico que tengas habilitado como cliente de la entidad.

Referencia: Samuelson, W. y Zeckhauser, R. (1988). Status quo bias in decision making. Journal of Risk and Uncertainty, 1, 7-59.

\section{¿Te «duele el bolsillo» cuando pagas?}
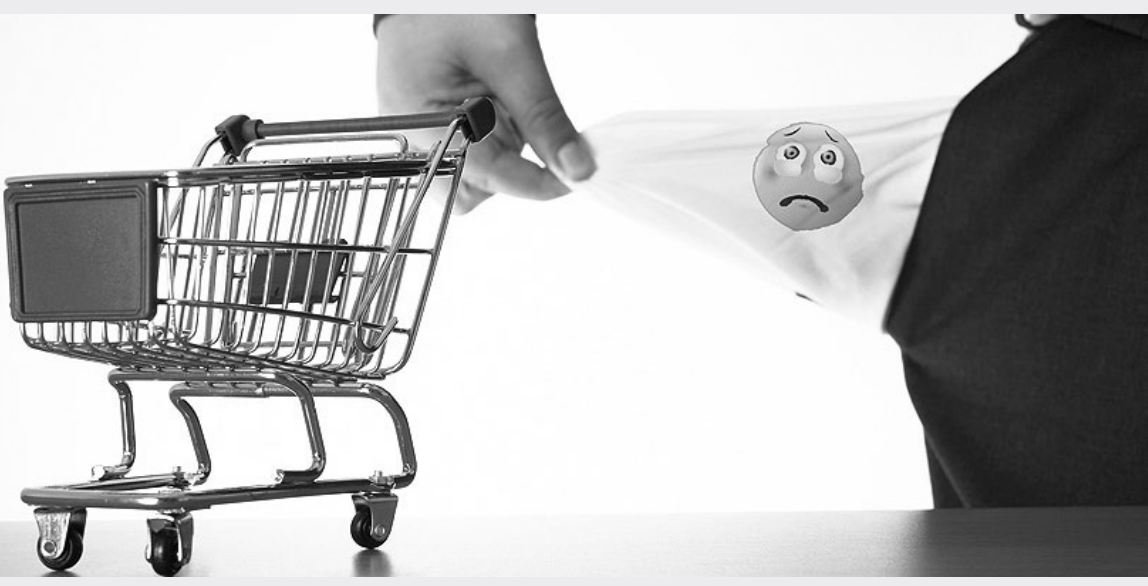

Fuente: https://clientebancario.bde.es/pcb/es/blog/duele_el_bolsillo.html 


\section{$21 / 11 / 2019$}

En la serie Decisiones con Cabeza, nos fijamos hoy en el dolor de pagar. Y es que, cuando pagamos, nos duele el bolsillo, pero no solo de manera metafórica, sino real: recientes estudios neurológicos han descubierto que este hecho estimula las mismas regiones cerebrales que el dolor físico.

Esta cruda realidad debiera estimular nuestra responsabilidad en las compras. Sin embargo, puede también inclinarnos hacia ciertos hábitos para minimizar ese daño, de los que debemos ser conscientes:

- Desvinculamos el momento de consumir del momento de pagar. Cuando pago y consumo coinciden en el tiempo, somos más conscientes de lo que estamos gastando y tendemos a disfrutar menos de la compra. En cambio, cuando pagamos antes o después de la compra, nos olvidamos del pago realizado (o pendiente de realizar) y el consumo nos parece casi gratis, resultándonos más placentero.

- Agrupamos pérdidas. Tendemos a agrupar los gastos para difuminar el dolor. Una amalgama de muchos pagos de diferente naturaleza reduce el impacto y el sufrimiento que nos hubiera producido cada uno de estos gastos por separado.

- Minimizamos la pérdida, haciéndola menos visceral. Cuanto menor es la atención que ponemos en el pago, menos doloroso nos parece. ¡Ojos que no ven, corazón que no siente!

Si lo meditas, el pago con tarjeta de crédito reúne las tres condiciones anteriores: separa temporalmente la compra del pago, liquida de una vez todos los cargos del mes y, además, nos hace ser menos conscientes del abono al tener simplemente que acercar el plástico o el dispositivo móvil al TPV, en vez de rebuscar en el monedero o en la cartera el dinero necesario para realizar el pago.

Frente al dolor de pagar y a nuestra tendencia por mitigarlo acudiendo a nuestra tarjeta de crédito, te proponemos dos estrategias para "poner cabeza» en las decisiones de consumo y evitar sobreendeudamientos:

- Estrategia 1. Establece tus propios límites, de uso y crédito, en tus tarjetas para controlar mejor los gastos.

- Estrategia 2. Combina el uso de las tarjetas de crédito con otros medios que no signifiquen más deuda, como tarjetas de débito y efectivo.

\section{«Efecto marco»}

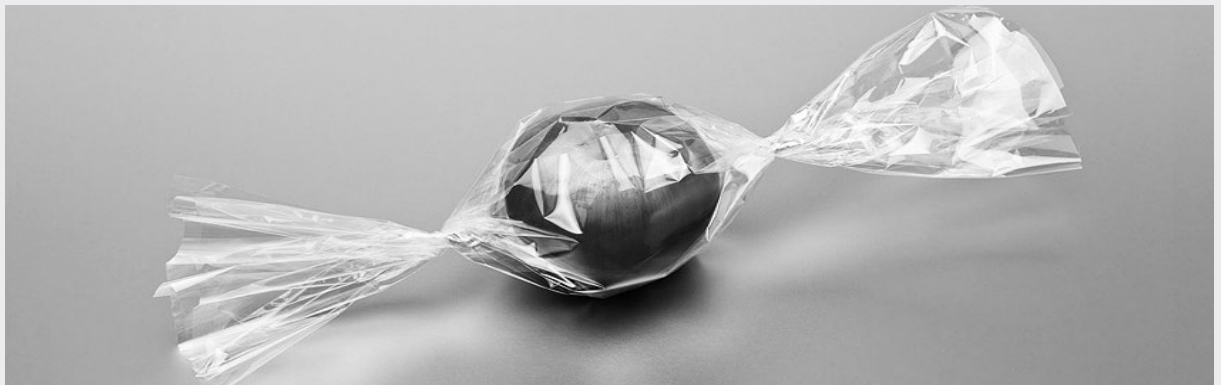

Fuente: https://clientebancario.bde.es/pcb/es/blog/efecto-marco.html 
$17 / 12 / 2019$

Factores como el orden de presentación del mensaje, la forma de plantear la información (el vaso medio lleno o medio vacío), los atributos del comunicador del mensaje, la credibilidad de la fuente informativa o el contexto en el que se emite la comunicación afectan a nuestras elecciones: jel envoltorio importa!

Este fenómeno, llamado "efecto marco", es ampliamente conocido en el ámbito del marketing y se usa para influir en las decisiones de consumo, también las que se refieren a la contratación de productos bancarios.

La publicidad de los productos financieros está sujeta a una normativa específica para garantizar la protección de los usuarios y el Banco de España supervisa su cumplimiento mediante la revisión de piezas de publicidad bancaria. Sin embargo, la existencia de autoridades de regulación y supervisión no nos exime como consumidores de nuestro insustituible papel a la hora de analizar la publicidad de un producto bancario antes de decidirnos por su contratación.

Ahora que se acercan fechas clave en las que nuestro consumo se puede disparar, te proponemos dos estrategias para «poner cabeza» en las decisiones de consumo y evitar el efecto marco:

- Estrategia 1. Si estás pensando en adquirir un bien o servicio, como, por ejemplo, un viaje, un aparato electrónico o un vehículo, presta atención a las condiciones de la financiación vinculada, ¡sin dejar de leer la letra pequeña!

- Estrategia 2. Fíjate especialmente en la TAE, ya que, independientemente de cuál sea el valor del tipo de interés nominal (TIN), si la TAE es positiva, la financiación te conllevará un coste. Haz cálculos con nuestro simulador.

\subsection{Una valoración de su impacto}

Para valorar el impacto de las series de posts publicadas se ha acudido a las métricas generadas por Webtrends (versión 9.2) para el periodo comprendido entre su publicación -en el segundo semestre de 2019- y el 31 de diciembre de 2020. Concretamente, la popularidad de cada uno de los posts se ha medido por el indicador «visualizaciones de páginas», que recoge los accesos registrados a los posts en cuestión, teniendo en cuenta que, si estos contienen imágenes y archivos incrustados, el acceso a los mismos cuenta como una sola visualización de página.

Los cuadros 3 y 4 muestran el número de visualizaciones recibidas por los posts de las series «Jeroglíficos Financieros» y «Decisiones con Cabeza», respectivamente. 
Cuadro 3. Impacto de la serie «Jeroglíficos Financieros»

\begin{tabular}{|c|c|c|}
\hline Página & Visualizaciones & Visitas \\
\hline Jeroglífico 1. Cancelación de un préstamo. & 1.044 & 614 \\
\hline Jeroglífico 2. Comisión por descubierto y tipos de comisiones. & 955 & 551 \\
\hline $\begin{array}{l}\text { Jeroglífico 3. Cambio de condiciones en el contrato de pro- } \\
\text { ductos bancarios. }\end{array}$ & 948 & 535 \\
\hline $\begin{array}{l}\text { Jeroglífico } 4 \text {. Tarjeta bancaria y qué hacer si me roban o clo- } \\
\text { nan la tarjeta. }\end{array}$ & 1.815 & 557 \\
\hline Jeroglífico 5. La TAE y la publicidad de productos bancarios. & 1.794 & 587 \\
\hline Jeroglífico 6. Préstamo personal y crédito al consumo. & 986 & 625 \\
\hline
\end{tabular}

Nota: se considera una visita el conjunto de acciones a partir de que un visitante visualiza la primera página desde el servidor hasta que deja el sitio o permanece inactivo durante más de 30 minutos.

Fuente: informe generado por WebTrends para el periodo comprendido entre el 1 de enero de 2019 y el 31 de diciembre de 2020.

\section{Cuadro 4. Impacto de la serie «Decisiones con Cabeza»}

\begin{tabular}{l|c|c|}
\hline \multicolumn{1}{c|}{ Página } & Visualizaciones & Visitas \\
\hline Presentación de la serie. & 979 & 567 \\
\hline Sesgo por el presente. & 1.017 & 624 \\
\hline Sesgo statu quo. & 1.364 & 789 \\
\hline Aversión a la pérdida. & 1.148 & 648 \\
\hline Efecto marco. & 1.033 & 616 \\
\hline
\end{tabular}

Fuente: informe generado por WebTrends para el periodo comprendido entre el 1 de enero de 2019 y el 31 de diciembre de 2020.

Los datos muestran un impacto de ambas series muy similar, tanto entre ellas como entre cada uno de los posts dentro de la misma serie, y cercano al millar de visualizaciones, superándolo con creces en algunos casos. Teniendo en cuenta que las secciones más visitadas del Portal del Cliente Bancario corresponden a aquellas eminentemente aplicadas, como las de los 
simuladores y los tipos de interés, y que, dentro de la sección «Blog», los posts más populares atañen asimismo a cuestiones de la máxima aplicación práctica (como qué hacer para cobrar un cheque o cuando fallece el titular de una cuenta), consideramos estos resultados como positivos e indicadores de haber conseguido provocar en el gran público cierto interés por las cuestiones financieras. En un entorno generalizado de escasa cultura financiera, se podría calificar esta iniciativa como un pequeño logro de educación financiera. En el siguiente y último apartado damos cuenta también de sus limitaciones y de las potencialidades detectadas.

\section{Limitaciones, potencialidades y conclusión}

Las dos series de contenidos publicados recogen gran parte de las recomendaciones de la OCDE para la educación financiera de los ciudadanos: ambas se han presentado como "píldoras de conocimiento» con un envoltorio ameno y atractivo, y las dos han hecho uso de canales digitales a través de su publicación en el Portal del Cliente Bancario y de su difusión a través de la cuenta de Twitter del Banco de España, entre otras vías, con el potencial de llegar a una amplia masa crítica de ciudadanos. Además, la serie de «Jeroglíficos Financieros» ha supuesto una clara apuesta por la gamificación de la educación financiera, original y creativa: no se tiene noticia de la existencia de ninguna otra serie de jeroglíficos financieros como los publicados en el Portal del Cliente Bancario. Por su parte, la serie de «Decisiones con Cabeza» ha dado a conocer los principales sesgos que pueden afectar a las decisiones bancarias, manteniendo al mismo tiempo una actitud positiva hacia las finanzas y ofreciendo herramientas para un mejor autocontrol y gestión (por ejemplo, a través de la herramienta del presupuesto personal o de simuladores y comparadores fiables, desarrollados por el Banco de España y Finanzas para Todos). Sin embargo, la propuesta sugerida adolece también de algunas limitaciones, resaltando el alcance, en términos de visualizaciones, de los posts publicados. Hay, ciertamente, un amplio margen de mejora para poder seguir sumando visualizaciones y llegar a más público.

Adicionalmente, en relación con la serie «Decisiones con Cabeza», reconocemos, en primer lugar, que las vinculaciones presentes en cada uno de los posts de «sesgo cognitivo» $\rightarrow$ «práctica financiera» $\rightarrow$ «estrategia concreta» son ciertamente simplistas, dado que las prácticas y usos financieros de la población no pueden atribuirse exclusivamente a la observancia de un sesgo o heurística, sino que dependerán de muchos otros factores, entre ellos, la interacción con otros posibles sesgos. No obstante, en aras de la claridad y simplicidad para el lector, se ha optado por dicho planteamiento, que en ningún caso debe entenderse como una relación causal unívoca.

En segundo lugar, la serie propuesta de contenidos no aborda otros sesgos y heurísticas de gran relevancia en la práctica bancaria, como podrían ser, por ejemplo, el «efecto manada», el 
«efecto legado» o el «sesgo de confirmación», por citar algunos. Somos conscientes de esta limitación y, de hecho, la contemplamos como una posible vía de ampliación de la serie de posts «Decisiones con Cabeza» en un futuro.

Por otra parte, es evidente que la economía de la conducta abarca muchos más aspectos que los comentados en este trabajo y que la educación financiera permite una mayor gama de iniciativas y acciones por parte de las autoridades para su promoción. Lo aquí presentado es una iniciativa muy concreta que podrá ir dando lugar a muchas otras que consideren todos o alguno de los hallazgos expuestos de la economía de la conducta.

Respecto a la serie de «Jeroglíficos Financieros», la principal limitación encontrada es su menor capacidad de conectar con un público más joven y menos familiarizado con los pasatiempos tradicionales. No obstante, en la medida en que el Portal del Cliente Bancario está destinado principalmente a la población adulta (los principales usuarios financieros), se trataría de una limitación de escaso impacto.

Finalmente, las conclusiones que pueden extraerse de la experiencia educativa descrita en este trabajo son las siguientes:

- La educación financiera va más allá de proporcionar conocimientos. Consiste también en educar en conductas y en promover comportamientos financieros saludables que posibiliten alcanzar un bienestar financiero personal y familiar sostenible a lo largo de las distintas etapas de la vida. Entre estas conductas se encuentran el uso de la herramienta del presupuesto, el ahorro activo (en la medida de lo posible), la revisión periódica de los movimientos de la cuenta y de nuestras finanzas personales, la información y comparación de distintas alternativas antes de la contratación de un producto financiero y la proyección a largo plazo de la economía personal y familiar (OCDE, 2017).

- Encontramos un gran potencial de las herramientas digitales para la educación financiera y, en particular, del Portal del Cliente Bancario debido a:

- Su alcance y disponibilidad a todos los ciudadanos (en julio de 2020 superó las 500.000 visitas mensuales y su tendencia es creciente).

- Su fácil accesibilidad (cuenta con opción de lectura fácil y con versión inglesa de todos los contenidos del portal).

- La imparcialidad y fiabilidad de la fuente de los contenidos y de las herramientas proporcionadas (el Banco de España y Finanzas para Todos).

- La puesta a disposición de calculadoras, simuladores, comparadores y otras herramientas digitales diseñadas por el propio Banco de España y por Finanzas para Todos.

- Su observancia de las recomendaciones de la OCDE. 
- Encontramos también un gran potencial de la economía de la conducta en la educación financiera de los ciudadanos, tanto para proporcionar conocimientos como para promover conductas financieras saludables; tanto para definir el contenido de los mensajes como la forma de transmitirlos, teniendo en consideración los sesgos y heurísticas en las que podemos incurrir. Para el caso concreto de la educación financiera, abogamos por una utilización de la economía de la conducta que potencie el «razonamiento sosegado» de los clientes bancarios y promueva unas decisiones acertadas, tomadas con responsabilidad, reflexión y sentido crítico.

Aplicaciones prometedoras que abren, ciertamente, nuevos e interesantes horizontes para garantizar una mejor educación financiera del ciudadano y, por extensión, una más eficiente protección del cliente bancario.

\section{Referencias bibliográficas}

Andújar Nagore, I. (2019). La economía de la conducta y la educación financiera del cliente bancario: una propuesta a través del Portal del Cliente Bancario. Programa de Desarrollo Profesional y Personal del Departamento de Teoría Económica y Economía Matemática de la Facultad de Ciencias Económicas y Empresariales de la Universidad Nacional de Educación a Distancia (UNED).

Andújar Nagore, I. y Tejada, F. (2019). La educación financiera: la otra cara del préstamo responsable. II Congreso Internacional de Educación Financiera de Edufinet «Educación Financiera para una Sociedad en Transformación». Málaga. Working Paper 5/2020. https://www.edufinet.com/images/EdufiA cademics/WP-5-2020.pdf

Ariely, D. y Kreisler, J. (2018). Las trampas del dinero. Ariel.

Baddeley, M. (2019). Behavioural Economics and Finance (2. ${ }^{\mathrm{a}} \mathrm{ed}$.). Routledge.

Banco de España y CNMV. (2008). Plan de educación financiera 2008-2012. Banco de España y CNMV. https://www.bde.es/f/web bde/Secciones/Publicaciones/OtrasPublica ciones/educacionfinaciera/PlanEducacion 2008_2012.pdf

Banco de España y CNMV. (2021). Plan de educación financiera 2018-2021. Banco de
España y CNMV. https://www.bde.es/f/webb de/Secciones/Publicaciones/OtrasPubli caciones/educacionfinaciera/PlanEducacion 2018_2021.pdf

Bover, O., Hospido, L. y Villanueva, E. (2016). Encuesta de competencias financieras (ECF) 2016: principales resultados. https:// www.bde.es/bde/es/areas/estadis/estadis ticas-por/encuestas-hogar/relacionados/ encuesta-de-comp/ECF_2016.html

Bucks, B. K. y Pence, K. M. (2008). Do borrowers know their mortgage terms? Journal of Urban Economics, 64(2), 218-33.

Campbell, J. Y., Jackson, H. E., Madrian, B. C. y Tufano, P. (2011). Consumer financial protection. Journal of Economic Perspectives, 25(1), 91-114.

DCE. (2019). Memoria de reclamaciones. Departamento de Conducta de Entidades del Banco de España. https://www.bde.es/f/ webbde/Secciones/Publicaciones/Publica cionesAnuales/MemoriaServicioReclamacio nes/19/Documentocompleto.pdf

DCE. (2020). Memoria de reclamaciones. Departamento de Conducta de Entidades del Banco de España. https://www.bde.es/f/web bde/Secciones/Publicaciones/Publicaciones Anuales/MemoriaServicioReclamaciones/ 20/MSR2020.pdf 
Fincham, R., Reynolds, R. y Spicer, N. (2015). Engagement with Current Accounts and the Switching Process. Research Report. Commissioned by The Financial Conduct Authority.

Hernández de Cos, P. (2019). Conocimientos y educación financiera de la juventud en España. Jornadas de Educación Financiera BBVA EduFin Summit 2019. Madrid.

Hernández de Cos, P., Jimeno, J. F. y Ramos, R. (2017). El sistema público de pensiones en España: situación actual, retos y alternativas de reforma. Documentos Ocasionales, 1.701, 1-53.

Hershfield, H. E., Goldstein, D. G., Sharpe, W. F., Fox, J., Yeykelis, L., Carstensen, L. L. y Bailenson, N. J. (2011). Increasing saving behaviour through age-progressed renderings of the future self. Journal of Marketing Research, 48. Special Interdisciplinary Issue 2011: Consumer Financial Decision Making (2011): S23-S37.

Kaheman, D. (2003). Maps of bounded rationality: psychology for behavioral economics. American Economic Review, 93(5), 1.449-1.475.

Kaheman, D. y Tversky, A. (1979). Prospect theory: an analysis of decision under risk, Econometrica, 47(2), 263-291.

Lusardi, A. y Mitchel, O. S. (2011). Financial literacy around the world: an overview. Journal of Pension Economics and Finance, 10(4), 497-508.

OCDE. (2009). Financial Literacy and Consumer Protection: Overlooked Aspects of the Crisis. OECD Recommendation.

OCDE. (2017). G20/OECD INFE Report: Ensuring Financial Education and Consumer Protection for all in the Digital Age. https://www. oecd.org/daf/fin/financial-education/G20OECD-INFE-Report-Financial-EducationConsumer-Protection-Digital-Age.pdf

OCDE. (2018). G20/OECD INFE Policy Guidance: Digitalisation and Financial Literacy. https://www.oecd.org/finance/G20-OECDINFE-Policy-Guidance-Digitalisation-Finan cial-Literacy-2018.pdf
OCDE. (2019). Smarter Financial Education: Key Lessons from Behavioural Insights for Financial Literacy Initiatives, 1-24. https://www. oecd.org/financial/education/smarter-finan cial-education-behavioural-insights.pdf

OCDE. (2020a). Launch of the OECD/INFE 2020 International Survey of Adult Financial Literacy. https://www.oecd.org/financial/education/ launchoftheoecdinfeglobalfinancialliteracy surveyreport.htm

OCDE. (2020b). PISA 2018 Results Nolume M): Are Students Smart about Money? PISA, OCDE Publishing, París. https://read.oecd. org/10.1787/48ebd1 ba-en?format=pdf

O'Donoghue, T. y Rabin, M. (1999). Doing it now or later. The American Economic Review, 89(1), 103-122.

Richard. B y Yong, Z. (2000). Consumer product evaluation: the interactive effect of message framing, presentation order, and source credibility. The Journal of Product and Brand Management, 9(4), 229-242.

Samuelson, W. y Zeckhauser, R. (1988). Status quo bias in decision making. Journal of Risk and Uncertainty, 1, 7-59.

Simon, H. A. (1955). A behavioural model of rational choice. Quarterly Journal of Economics, 69, 293-118.

Soman, D. (2001). Effects of payment mechanism on spending behaviour: the role of rehearsal and immediacy payments. Journal of Consumer Research, 27, 460-474.

Thaler, R. H. (1999). Mental accounting matters. Journal of Behavioral Decision Making, 12, 183-206.

Tversky, A. y Kahneman, D. (1974). Judgment under Uncertainty: Heuristics and Biases. Science, 185(4.157), 1.124-1.131.

Tversky, A. y Kahneman, D. (1981). The framing of decisions and the psychology of choice. Science, 211, 453-458.

Van Raaij, V. F. (2016). Understanding consumer Financial Behaviour. Money Management in an Age of Financial Illiteracy. Palgrave Macmillan. 